\title{
CONSTRUCTION PLANNING FOR GANG FORMWORK REUSE USING SIMULATION
}

\author{
Rong-Yau Huang, Ph.D, Kuo-Shun Sun, Jeam-Jei Chen \\ Associate Professor, Dept. of Civil Engineering, National Central \\ University, Chung-li, Taiwan 32054,ROC \\ Lecturer, Dept. of Civil Engineering, Fu-Shin Instistute of Technology, I- \\ Lan, Taiwan 261,ROC \\ Master Graduate, Dept. of Civil Engineering, National Central University, \\ Chung-li, Taiwan 32054,ROC
}

\begin{abstract}
Concrete formwork is a labor-intensive and time-consuming operation. Many modular formwork systems have been developed to automate the formwork construction and to improve its productivity and cost effectiveness. Usually, proper planning in architechtual design of building, form reuse scheme, resource allocation (modular form sets, cranes, workers, etc.), and construction sequence is required to ensure the success use of a modular formwork system. Many real world cases prove that application of modular formwork systems for building construction is almost deemed to be unsuccessful without proper planning.

Computer simulation is a valuable management tool well suited to the study of resource driven operations. It gives the analyst an insight into resource interaction and assists in identifying the non value-adding tasks in a process. Different scenarios can be evaluated for better construction planning and analysis. Simulation is employed in this research to study the productivity and cost effectiveness of different form construction schemes for the use of gang forming systems. Five form construction schemes are identified and the CYCLONE modeling methodology is employed for the development of computer models for each of them. Sensitivity analysis on different numbers of form sets, cranes, and crews is then conducted using a real-world case to analyze their respective impacts on the productivity as well as the cost effectiveness of the operation. The objective is to better understand the characteristics of the different form construction schemes and to achieve better plans for gang forming construction. Thus, the application of the modular formwork systems can be facilitated.
\end{abstract}

Keywords: Construction, Planning, Formwork, Simulation.

\section{INTRODUCTION}

Reinforced-concrete (RC) has been the major structure type for buildings in Taiwan. Almost $87 \%$ of the total building floors are made of RC structure [1]. One of the major activities in the construction of a $\mathrm{RC}$ building is concrete formwork. According to statistics, formwork takes up to $15 \%$ of the total construction cost or $1 / 3$ of the concrete cost item [2]. The traditional concrete formwork system is characterized as labor-intensive and time-consuming. Not only concrete forms are usually assembled manually on site, but also the concrete surface after form stripping is usually rough and requires further finishing. In addition, formwork is also the main cause of the casualties in construction. Consequently, the activity of formwork is frequently on the critical path of a project and affects the project in duration, cost, quality, and safety.

Here is my introduction text. There are 2 blank lines before the section heading and one afterwards. Heading text is 12 point font. I may want a numbered subsection. which is done as follows.

Substantial efforts have been invested in the past few decades to automate the formwork operation and to increase the productivity. Many modular formwork systems are developed as a result [3]. Modular formwork systems employ prefabricated forms with standard sizes. Form erection is made easier by putting the right forms in the right places. In the case that larger size of forms is used, such as gang forming systems, cranes are required to assist in the operation. The modular formwork systems have the following advantages:

(1) The erection time is shortened substantially. 
(2) Due to the standardized and simple installing procedure, less labor skills is required.

(3) The prefabricated form set can be reused over and over again within and across projects. Therefore less material loss is resulted and cost effectiveness is improved.

(4) The higher strength of the form set potentially increases the safety for subsequent concrete pouring task and reduces the casualty in construction.

(5) The smooth surface of the form set eliminates the need for further finishing work after form stripping.

Nonetheless, a proper plan for the reuse of the form set is needed to make those advantages realized. A proper form reuse scheme can not only increase the number of times for form reuse, but also shorten the erection time so that the cost effectiveness for adapting the modular formwork system can be achieved. Many real world cases applying modular formwork systems are found to be unsuccessful because of the lack of proper planning. In some cases, the form erection time is increased, cost is not justified, and/or quality is not satisfied. Therefore, a proper planning for form reuse is definitely critical to bring out the benefits of adapting the modular formwork system [4].

Among different modular formwork systems, gang forming systems deal with larger sizes of forms and require the assistance of cranes. It then normally involves more complex resource planning and scheduling. This paper investigates and identifies the different modes for form reuse schemes for the gang forming system. Computer simulation is employed for modeling of the different schemes. Sensitivity analysis is conducted to compare their cost and time effectiveness. The goal is to better understand the different form reuse schemes and to facilitate the use of modular forwork system for concrete construction.

\section{REUSE SCHEMES OF GANG FORMING SYSTEMS}

The reuse scheme of a modular formwork system involves the decision on the number of regions divided on each building floor, the number and service capacity of cranes, the set number of horizontal and vertical forms, the number of crews, the sequence among activities used in the project, and so on. Based on interviews with superintedents or formen on several construction sites employing the gang forming system and also on interviews with the formwork agents, five reuse schemes are identified and described as follow:

\subsection{Reuse Scheme 1: Single region (SR)}

The whole building area (could be single or multiple buildings) in the same floor is divided as one single region for formwork construction and form reuse. The form set is then reused only vertically. In addition, service cranes serves exclusively for the region. As shown in figure 1, the shadow area represents the floor area in a region and a form set to cover the whole region is prepared. Circles in figure 1 depict the area covered by the booms of the service cranes. Figure 1(a) illustrates a "single region" reuse scheme for a single building construction and figure 1(b) for multiple buildings. This reuse scheme is frequently used in projects with smaller building floor area in each floor. As the building floor areas become larger, further division of the floor area into more regions may be considered to expedite the construction, and that means more form sets, cranes, and/or crews have to be introduced at the same time.

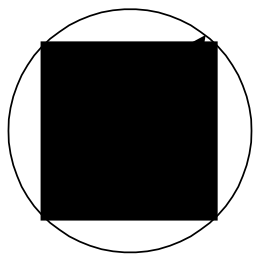

(a)

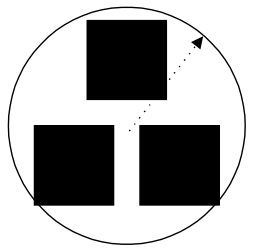

(b)
Figure 1. The "Single Region" Scheme

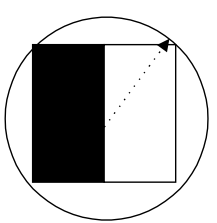

(a)

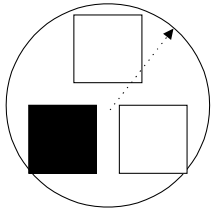

(b)

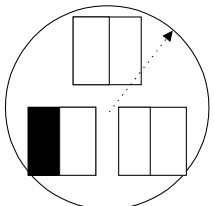

(c)
Figure 2. The " MR/CS/FS " Scheme

\subsection{Reuse Scheme 2: Multiple regions with cranes and forms shared (MR/CS/FS)}

In the $\mathrm{MR} / \mathrm{CS} / \mathrm{FS}$ scheme, the single floor area is divided into multiple regions for horizontal form reuse. Both form set(s) and crane(s) are shared in the multiple regions for construction. Figure 2 illustrates the reuse scheme. In figure 2(a), only one building is involved in the scheme and its floor area is divided into two regions. Form set(s) is/are shared for horizontal reuse in the two regions. In addition, the service tower crane(s) is/are shared as well in the two regions. In figure 2(b) and 2(c), multiple buildings are involved in the scheme. However, instead of using one building floor as a region in 2(b), each building floor is further divided into two regions in 2(c). The MR/CS/FS scheme is the most used reuse scheme in the project sites adapting the gang forming system. It has the advantages of making the form reuse number higher, increasing the utilization of the tower cranes, lowering the manpower requirement, 
and increasing the work efficiency. This reuse scheme is cost effective for the projects with comfortable completion time. In the cases where project completion time is in pressing, increasing of the number of form sets as well as other resources, or using other schemes can be considered.

\subsection{Reuse Scheme 3: Multiple regions with cranes shared and form not shared (MR/CS/FNS):}

Similar to the MR/CS/FS scheme, the single floor area is divided into multiple regions in the $\mathrm{MR} / \mathrm{CS} / \mathrm{FNS}$ scheme. However, only crane(s) is/are shared in the multiple regions for construction. Each region is equipped with its own set of forms and only reused vertically. Figure 3 illustrates the reuse scheme. In figure 3(a), single building is involved in the scheme and its floor area is divided into two regions sharing the service crane(s). Each of the two regions has its own set of forms. In figure 3(b), multiple buildings are involved and each building floor area or region has its own set of forms. In figure 3(c), each building floor area is further divided into two regions. There are totally six regions. This reuse scheme is used when the project completion time is compelling. However, construction cost could be higher as a result.

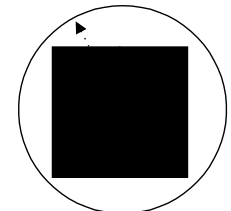

(a)

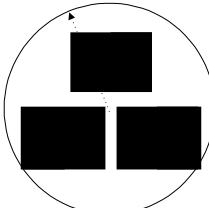

(b)

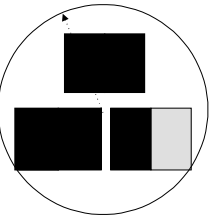

(c)
Figure 3. The " MR/CS/FNS " Scheme

\subsection{Reuse Scheme 4: Multiple regions with cranes not shared and form shared (MR/CNS/FS)}

In the $\mathrm{MR} / \mathrm{CNS} / \mathrm{FS}$ scheme, form $\operatorname{set}(\mathrm{s})$ is/are shared for horizontal reuse in the multiple regions. However, each region will have its own service crane(s). Figure 4 illustrates the reuse scheme. In figure 4(a), single building is involved in the scheme and its floor area is divided into two regions. Form set(s) is/are shared and horizontally reused in the two regions. But each region has its own service crane(s). Similar situation can be found in figure 4(b) and 4(c) except multiple buildings are involved in the reuse scheme. This reuse scheme is used when other activities in project also demand a lot the service of tower crane(s). In order to avoid delay caused by the crane unavailability, more cranes are used in this scheme.

2.5 Reuse Scheme 5: Multiple regions with cranes and forms not shared (MR/CNS/FNS)
In the MR/CNS/FNS scheme, the whole building area (could be single or multiple buildings) in the same floor is divided into multiple regions. Each region has its own set(s) of forms and service cranes(s). In other words, each region operates just like the single region in the reuse scheme 1. Figure 5 illustrates the reuse scheme. In figure 5(a), single building is involved and its floor area is divided into two regions. Each of the two regions has its own set of forms and service cranes. In figure 5(b) and 5(c), multiple buildings are involved and each region has its own set of forms. With the exception that the project completion time is in some kind of urgency, this reuse scheme is seldom used in a regular project.

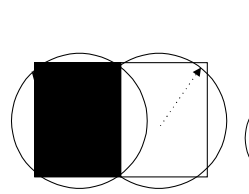

(a)

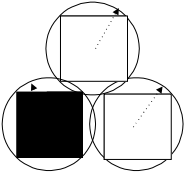

(b)

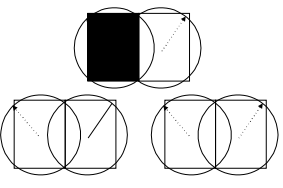

(c)
Figure 4. The " MR/CNS/FS " Scheme

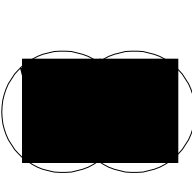

(a)

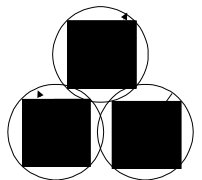

(b)

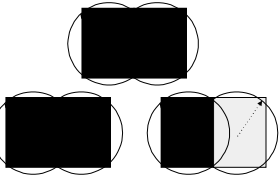

(c)
Figure 5 The " MR/CNS/FNS " Scheme

\section{STANDARD MODEL FOR THE GANG FORMWORK OPERATION}

Computer simulation is a valuable management tool which is well suited to the study of resource driven processes. It gives the analyst an insight into resource interaction and assists in identifying which factors in a problem domain are important. Simulation allows the modeler to experiment with and evaluate different scenarios. Normally, such experimentation and study would be too costly to be carried out in the real world.

Interests of applying simulation techniques for the planning and analysis of construction operations have been generated since the introduction of CYCLONE methodology by Halpin in 1973. Numerous examples of construction process models are given in Halpin [5], and Halpin and Riggs [6]. They include earth moving, pavement, tunneling, segmental construction of an elevated structure, and concrete placement in a high-rise building. The cyclic as well as the complex and dynamic aspects of construction operations make computer simulation a promising technique for the engineering analysis. Readers are referred to Halpin and Riggs [6] for details regarding the CYCLONE modeling methodology. 


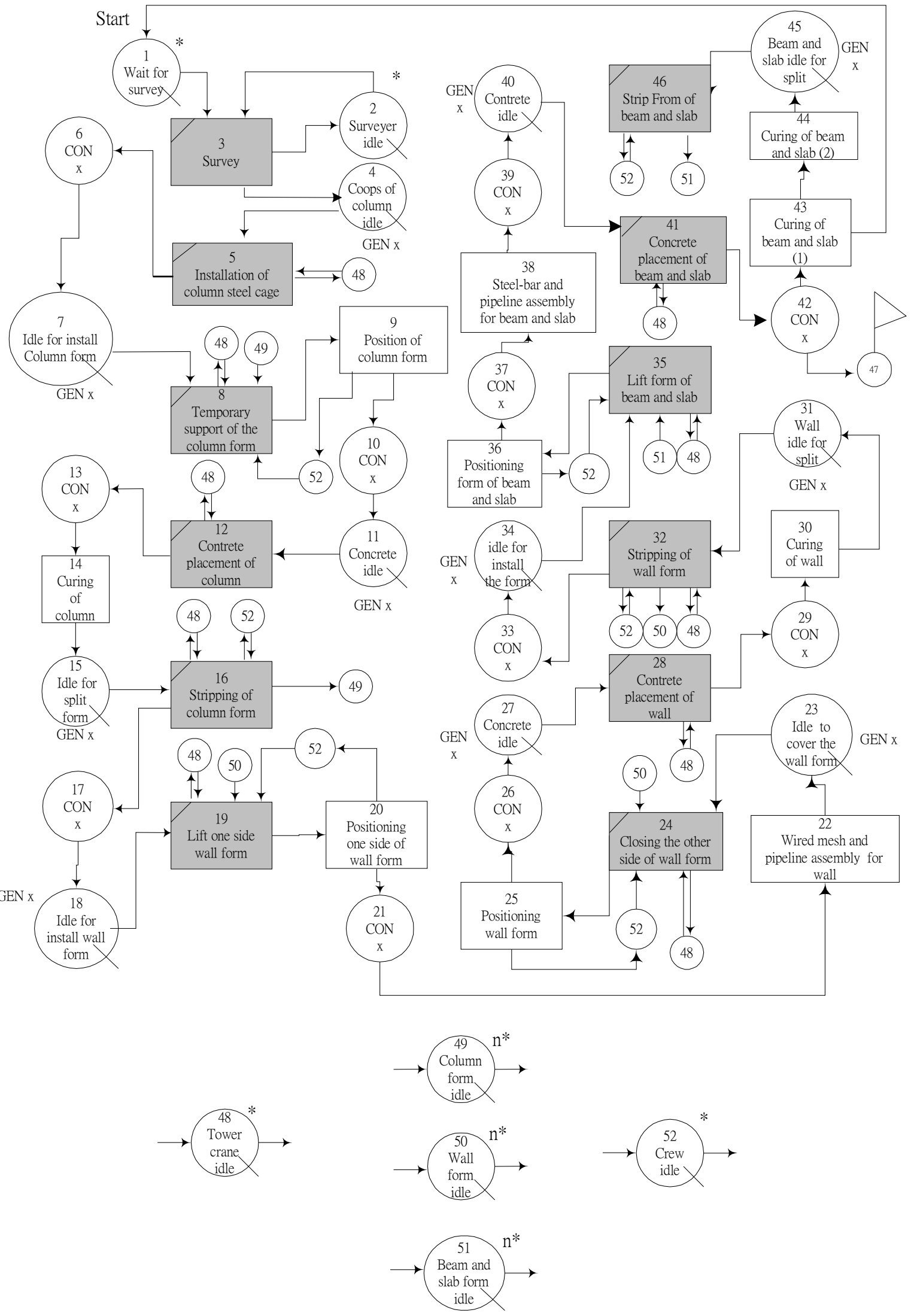

Figure 6 The standard CYCLONE Model for the Gang Forming Operation 
DISCO[7] is a prototype program developed for the modeling and simulation of construction operations. It basically serves as both a preprocessor and post processor for the CYCLONE program. DISCO builds a schematic model diagram graphically on the screen and generates the CYCLONE input file. It then takes the chronological list file generated by running the CYCLONE program as its input and recreates the entire course of simulation dynamically on the computer screen with the schematic model diagram used as the display mechanism. Thus, application of simulation for the planning and analysis of construction operations can be greatly facilitated.

The DISCO/CYCLONE simulation system is used in this paper to analysis the reuse model of the gang forming system.

Using the CYCLONE modeling methodology, a standard model of the gang form erection operation is developed and shown as figure 6 . The operation is consisted of 22 major activities (Table 2). Basically it follows the sequence of surveying, column erection, wall erection, and finally the erection of beam and slab. Major resources required in the operation include column form (node 49), wall form (node 50), beam and slab form (node 51), crew (node 52), and crane (node 48). Gen X (node 4) and Con X (node 6) are used in the model to repeat an activity or a sequence of activities as many times as needed. For instance, node 4 (Gen X) and 6 (Con X) are used to repeat the activity of "Installation of column steel cage" as many times as the number of columns on the floor. Whenever the counter of the model (node 47) is reached, a complete cycle for form erection of one region is finished and the productivity of the system is calculated.

As site conditions and resource allocation vary with different construction projects, the standard model represents the regular sequence of gang form erection operation. The number of resources and the control numbers for Gen and Con can be adjusted to reflect the actual situations in a project.

\section{MODELLING OF FIVE REUSE SCHEMES}

Simulation model for each of the five reuse schemes can be developed by modifying the standard model. They are described as follows:

1. SR: Since the standard model is developed for the form erection of a single region, it can be used directly to represent the operation using the SR scheme.

2. $\mathrm{MR} / \mathrm{CS} / \mathrm{FS}$ : The form erection operation in each of the multiple regions is represented by the standard model. In other words, the whole model of this scheme consists of the same number of standard models as of regions. However, since crane(s) and form set(s) are shared in all regions, each of the standard models will share the same resource nodes, e.g., column form (node 49), wall form (node 50), beam and slab form (node 51), crew (node 52), and crane (node 48).

3. MR/CS/FNS: In this case, since each of the multiple regions will have its own set(s) of form, each of the standard models will have separate set of form resource nodes (node 49-51) with different node numbers for differentiation. The rest of the model is the same as that of MR/CS/FS scheme.

4. MR/CNS/FS: Each of the multiple regions will have its own service cranes in this case. Therefore, each of the standard models will have a separate crane resource nodes (node 48) with different node numbers for differentiation. The rest of the model is the same as that of MR/CS/FS scheme.

5. MR/CNS/FNS: Since each of the multiple regions will have its own set(s) of form as well as crane(s), the model for this scheme is a collection of a number of standard models. The number is the same as the number of regions didvided.

\section{CASE STUDY - GANG FORMWORK OPERATION IN AN APARTMENT BUILDING PROJECT}

\subsection{Project Description}

Part of an apartment building project in Taoyaun, Taiwan is used as the case study to validate the developed models and to denmonstrate the use of simulation for the planning of the reuse schemes for adapting the gang forming system. The project is to build totally twenty 12-13 floors apartment buildings. The buildings are all RC structure and gang forming system is employed for concrete construction. The total floor area is more than five hundred thousand square meters. All interior walls are constructed by the reinforced concrete. Foreign laborers are employed in this project.

Table 1 Construction Information For Each Building Floor ( Region)

\begin{tabular}{|l|c|l||}
\hline \multicolumn{1}{|c|}{ Item } & Quantity & \multicolumn{1}{|c|}{ Remark } \\
\hline Form area used per story & $1580 \mathrm{~m}^{2}$ & \multicolumn{1}{|c||}{} \\
\hline -column form & $133 \mathrm{~m}^{2}$ & Totally sixteen column \\
\hline -wall form & $693 \mathrm{~m}^{2}$ & $\begin{array}{l}\text { Thirty-one walls, sixty-two } \\
\text { wall forms needed for two } \\
\text { sides }\end{array}$ \\
\hline -form of beam and slab & $754 \mathrm{~m}^{2}$ & Needs ten times of lifting \\
\hline $\begin{array}{l}\text { Concrete volume per } \\
\text { story }\end{array}$ & $263 \mathrm{~m}^{3}$ & $\begin{array}{l}\text { Need concret placed twice } \\
\text { per column, thirty-two } \\
\text { times total }\end{array}$ \\
\hline $\begin{array}{l}\text {-columns } \\
\text {-walls }\end{array}$ & $44 \mathrm{~m}^{3}$ & Fifty times total \\
\hline -beams and slabs & $190 \mathrm{~m}^{3}$ & $\begin{array}{l}\text { Two hundard times by } \\
\text { bucket }\end{array}$ \\
\hline
\end{tabular}




\begin{tabular}{|l|c|l|}
\hline Bucket volume & $1 \mathrm{~m}^{3}$ & \\
\hline Tower crane 550tm & 1 & $\begin{array}{l}\text { Service range cover the } \\
\text { three buidings }\end{array}$ \\
\hline $\begin{array}{l}\text { Form crew (a Taiwanese } \\
\text { and four foreign workers) }\end{array}$ & $\begin{array}{l}8 \text { crews } \\
\text { per day }\end{array}$ & $\begin{array}{l}\text { Two shifts, total work time } \\
\text { is sixteen hours per day }\end{array}$ \\
\hline
\end{tabular}

This research observed and collected data for the construction of 3 of the 20 buildings for the study. The 3 buildings are all 12 floors. For the form erection, $\mathrm{MR} / \mathrm{CS} / \mathrm{FS}$ sheme is adapted in this project for form reuse. There are three regions with each building floors being a region. Table 1 is the construction information regarding each building floor.

Table 2 lists the duration for each of the activities in the formwork operation. Most of the data are collected on the job site observing the actual work execution. Few items are obtained by interviewing the field personnel. In this project, one set of column and wall form, and two sets of beam and slab form are used in each region.

Table 2 Activity Duration in Form Erection Operation

\begin{tabular}{|c|l|c||}
\hline $\begin{array}{c}\text { Node } \\
\text { No. }\end{array}$ & \multicolumn{1}{|c|}{ Activity } & $\begin{array}{c}\text { Duration } \\
\text { (hr) }\end{array}$ \\
\hline 3 & Survey & 4 \\
\hline 5 & Installation of column steel cage & 0.33 \\
\hline 8 & Temporary support of column form & 0.15 \\
\hline 9 & Positioning the column form & 0.08 \\
\hline 12 & Concrete placement of column & 0.1 \\
\hline 14 & Curing of column & 14 \\
\hline 16 & Stripping of column form & 0.17 \\
\hline 19 & Lift one side wall form & 0.17 \\
\hline 20 & Positioning one side of wall form & 0.09 \\
\hline 22 & Wired mesh and pipeline assembly for wall & 4 \\
\hline 24 & Closing the other side of wall form & 0.2 \\
\hline 25 & Positioning wall form & 0.1 \\
\hline 28 & Concrete placement of wall & 0.1 \\
\hline 30 & Curing of wall & 14 \\
\hline 32 & Stripping of wall form & 0.13 \\
\hline 35 & Lift form of beam and slab & 0.2 \\
\hline 36 & Positioning form of beam and slab & 7 \\
\hline 38 & $\begin{array}{l}\text { Steel-bar and pipeline assembly for beam and } \\
\text { slab }\end{array}$ & 42 \\
\hline 41 & Concrete placement of beam and slab & 0.07 \\
\hline 43 & Curing of beam and slab (1) & 14 \\
\hline 44 & Curing of beam and slab (2) & 280 \\
\hline
\end{tabular}

In addition, the following assumptions are made for the modelling and the analysis of the operation:

1. Since the formwork workers were pre-trained to be familiar with the formwork system one week before the job got started, so the labor learning effect is neglected in the analysis.

2. The tower crane will climb up once every completion of three stories and the procedure takes about two days to complete. In order to avoid delay on project schedule, the crane usually climbs right after the completion of slab concrete placement. Hence, the crane climbing time does not affect the work progress and therefore is neglected in the analysis.

3. The partition design is not exact the same for each of the three buildings. However, to facilitate the anaysis, they are not differentiated.

4. In the normal practice the side form of beam can be strip earlier than the bottom ones to be used in the next position. However, since the side forms share only a small part of the total form cost (less than $2 \%$ ), they are treated the same as the bottom ones.

5. The initial form purchasing cost forms is apportioned completely in this project with no salvage value left.

Based on the above information, the formwork opeartion model is simulated for 36 cycles (3 buildings $\times 12$ floors each). The total project duration is 2,689 hours or 192 days ( $14 \mathrm{hrs} /$ day) and the average construction time is 16 days per story. According to the job superintedent, the average construction time in their project is about 15 days per story. The difference could result from the fact that the project has to rush their schedule from time to time to meet the owner's demand. However, steadystate condition is assumed in the simulation. Hence, the simulation result is one day longer per story than that in the real world. 
Table 3 Summary of the cases

\begin{tabular}{|c|c|c|c|c|c|c|c|}
\hline \multirow[b]{2}{*}{ Condition } & \multirow[b]{2}{*}{$\begin{array}{c}\text { Duration } \\
\text { (Days) }\end{array}$} & \multirow[b]{2}{*}{$\begin{array}{c}\text { Cost } \\
\text { (NT\$) }\end{array}$} & \multirow[b]{2}{*}{ Reuse scheme } & \multicolumn{4}{|c|}{ Resource needed } \\
\hline & & & & $\begin{array}{l}\text { Tower } \\
\text { cranes }\end{array}$ & $\begin{array}{l}\text { Column } \\
\text { and wall } \\
\text { form sets }\end{array}$ & \begin{tabular}{|c|}
$\begin{array}{c}\text { Beam and } \\
\text { slab form } \\
\text { sets }\end{array}$ \\
\end{tabular} & $\begin{array}{l}\text { Form } \\
\text { crews }\end{array}$ \\
\hline The lowest cost & 130 & $30,493,286$ & $\mathrm{MR} / \mathrm{CS} / \mathrm{FS}$ & 3 & 1 & 6 & 6 \\
\hline \multirow{2}{*}{ The shortest duration } & \multirow{2}{*}{100} & $96,244,071$ & $\mathrm{MR} / \mathrm{CNS} / \mathrm{FNS}$ & 9 & 3 & 9 & 30 \\
\hline & & $97,940,571$ & $\mathrm{MR} / \mathrm{CNS} / \mathrm{FNS}$ & 9 & 3 & 12 & 30 \\
\hline The highest cost & 259 & $189,678,214$ & $\mathrm{MR} / \mathrm{CNS} / \mathrm{FNS}$ & 9 & 3 & 3 & 30 \\
\hline The longest duration & 354 & $72,447,614$ & SR & 1 & 3 & 3 & 6 \\
\hline $\begin{array}{l}\text { The lowest cost scheme with the limit that the } \\
\text { duration to be under } 120 \text { days }\end{array}$ & 104 & $61,447,714$ & $\mathrm{MR} / \mathrm{CS} / \mathrm{FNS}$ & 3 & 3 & 12 & 12 \\
\hline $\begin{array}{l}\text { The shortest duration scheme with the limit that } \\
\text { the cost to be under NT } \$ 40,000,000\end{array}$ & 126 & $39,081,857$ & $\mathrm{MR} / \mathrm{CS} / \mathrm{FS}$ & 3 & 1 & 6 & 10 \\
\hline
\end{tabular}

\subsection{Sensitivity Analysis}

Sensitivity analysis on the five different reuse schemes with various resource allocation senarios is then conducted to determine the better options. Based on different reuse schemes (scheme 1 to 5) and the various quantity of tower cranes (1 to 9), column form set ( 1 to 3 ), wall form set ( 1 to 3 ), beam and slab form set ( 3 to 12 ), and crews (6 to 30 ), the computer simulation results can be ploted as a decision-making support diagram as shown in Figure 7. The horzital axis represents project cost (million NT\$) and the vertical axis the project duration (days). It can be seen from figure 7 that the "MR/CS/FS" scheme with 3 tower cranes, 1 column and wall form set, 6 beam and slab form sets, and 6 form crews yields the lowest cost (NT\$30,493,286). In this case, the project duration is 1823 hours or 130 days. On the other hand, there are two cases yield the shortest project duration (1405 hours or 100 days). The first case is "MR/CNS/FNS" scheme with 9 tower cranes, 3 column and wall form sets, 9 beam and slab form sets, and 30 form crews. The total cost is NT\$96,244,071. The other case is the same reuse scheme with 9 tower cranes, 3 column and wall form sets, 12 beam and slab form sets, and 30 form crews. The total cost is NT $\$ 97,940,571$.

It can also be seen from figure 7 that in the situations where the resources are insufficient or poorly allocated, or improper reuse scheme is adapted, the project duration could be as long as 354 days (SR scheme with 1 tower crane, 3 column and wall form sets, 3 beam and slab form sets, and 6 form crews), or the total cost could be as high as NT\$189,678,214 (MR/CNS/FNS with 9 tower crane, 3 column and wall form sets, 3 beam and slab form sets, and 30 form crews). Table 3 summarized the above cases.

\subsection{Decision Support Application}

In the situations where project duration or available cost are constrained, a decision line can be drawn on the decision support diagram as shown in figure 7 to determine the best option for the formwork operation. For instance,

1. if the project duration is limited to be under 120 days, a horzontal decision line can be drawn on the diagram in figure 7 and the case with the lowest total cost $(\mathrm{NT} \$ 61,447,714)$ can be determined. It employs the "MR/CS/FNS" scheme with 3 tower cranes, 3 column and wall form sets, 12 beam and slab form sets, and 12 form crews. The project duration is 104 days.

2. If the available form construction cost is constrained to be under NT\$40,000,000, then a vertical decision line can be drawn to determine the case with the shortest project duration (126 days). The result case employs "MR/CS/FS" reuse scheme with 3 tower cranes, 1 column and wall form set, 6 beam and slab form sets, and 10 form crews. The total cost is NT\$39,081,857. 


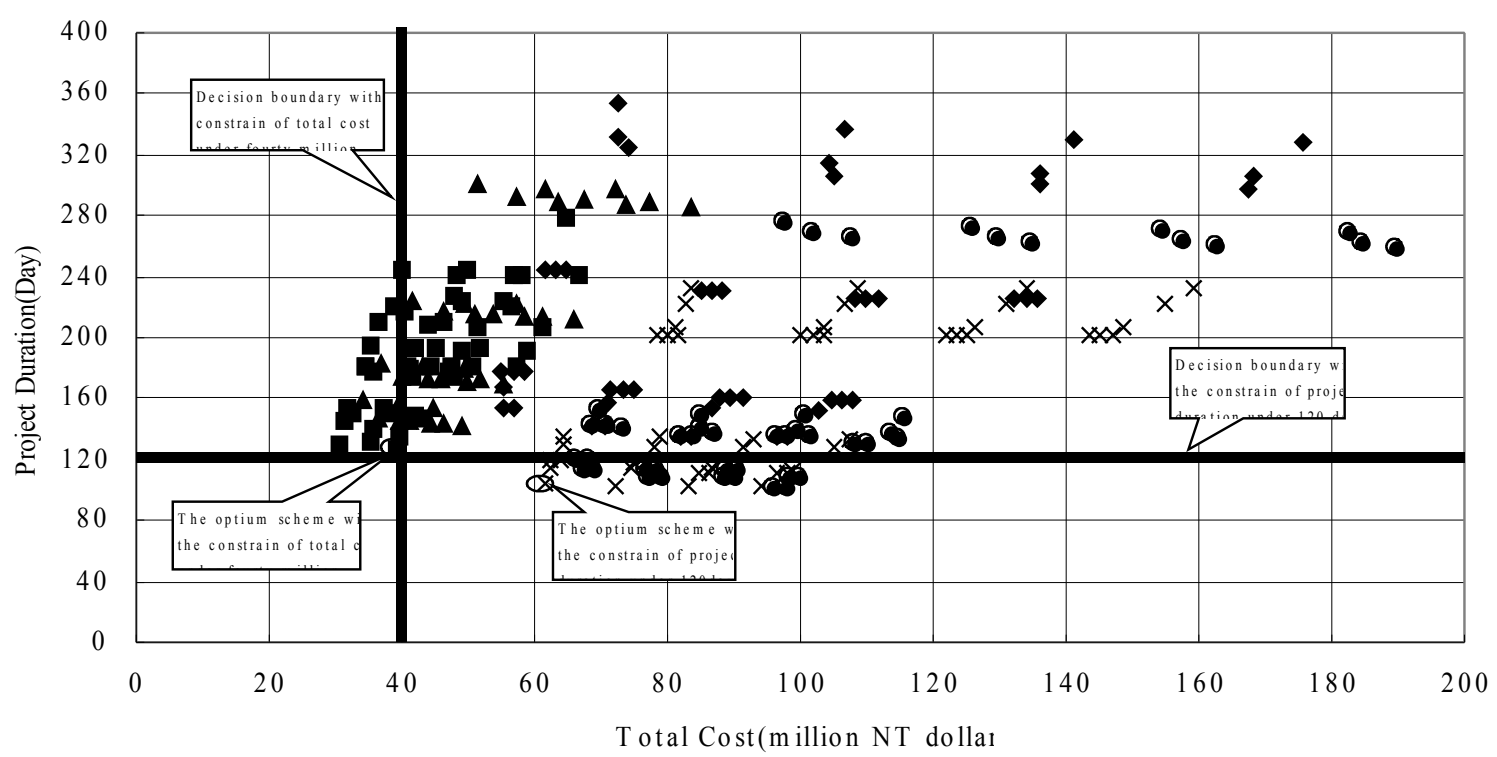

Figure 7. The Decision-making Diagram for the Gang Formwork Operation

The decisions on selecting the proper form reuse scheme and on planning for optimum resource allocation are affected by the architectural design of individual building in the project, configuration of buildings, site conditions, resource availability, cost and time constraints, and many other factors. It is definitely not a simple problem to solve. Computer simulation and decision support diagram provides an effective approach to assist in the planning of gang formwork operation. Figure 8 illustrates step by step the process for using this appoach. Each of the steps is described below.

1. Indentify the planning objectives and/or constraints.

2. Set the limits on the number of regions can be divided and on the available numbers for different resource types.

3. Based on the five gang form reuse schemes, set the possible alternatives for combinations of different region and resource numbers.

4. Employ the DISCO program and the standard gang form erection model to develop the proper model and to generate the input data for computer simulation.

5. Simulation the opeation using the CYCLONE program.

6. Draw the project time/cost decision-making support diagram based on the simulation results of all combinations for the gang forming operation.

7. Decide on the optimum alternatives for the gang forming operation based on the planned objectives and/or constraints.

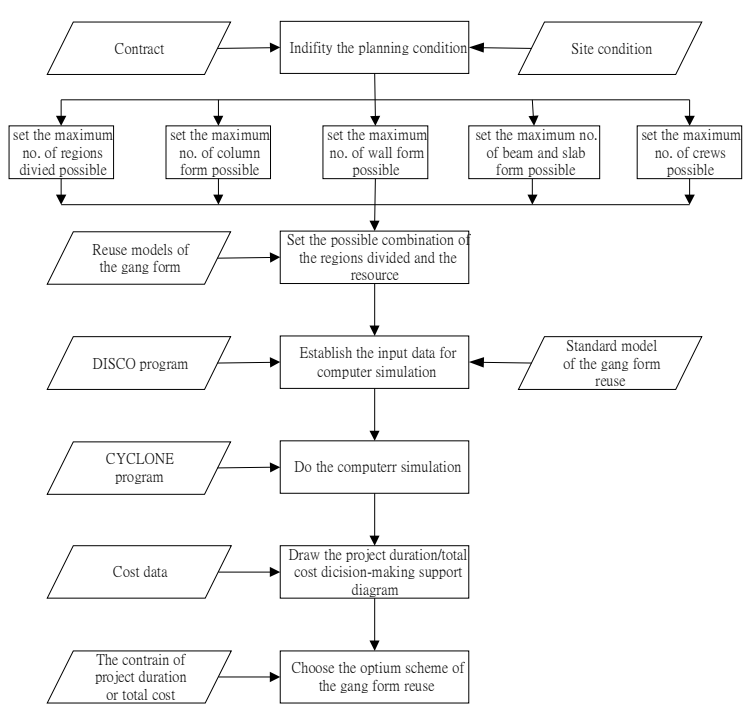

Figure 8. Decision-Making Strategy For Gang Forming Operation

\section{CONCLUSIONS}

1. Modular formwork systems can automate the formwork construction and to improve its productivity and cost effectiveness. However, a proper planning is critical to bring out their advantages.

2. Five gang form reuse schemes are identified in this research. They can assist in more effective planning and analysis of the gang formwork operation. 
3. The standard computer simulation model for the gang form operation is established in this study. The standard model can be modified easily to reflect the actual project site conditions.

4. Computer simulation techniques with the development of the decision-making support diagram provide an effective approach for determing the optium form reuse scheme and resource allocation, given the constraints of time and cost. Thus, application of modular formwork systems for concrete construction can be facilitated.

\section{REFERENCES}

[1] 彭雲宏等人,集合住宅施工自動化個案研究 (三) - 模板施工自動化之研究, 內政部建築研究所 籌備處, 1994 .

[2] 賴明茂、徐敏斯, "模板工法之比較分析與新技 術引進之探討", 中華民國建築學報,第六期, pp. 75103,1992.
[3] 楊松錦,建築工程模板作業評選架構之研究, 碩 士論文,國立台灣科技大學營建工程技術研究 所,1997.

[4] 蔡洲影,系統模板在營建工程應用上之評估模 式研究,碩士論文,國立台灣大學土木工程研究 所, 1995 .

[5] Halpin D. W., MicroCYCLONE User's Manual, Purdue University, Indiana 1990.

[6] Halpin D. W. and Riggs, L. S., Planning and Analysis of Construction Operations, John Wiley and Sons, INC., N. Y., 1992.

[7] Huang, Rong-Yau and Halpin, D. W., "Visual Construction Operation Simulation - The DISCO Approach", Journal of Microcomputers in Civil Engineering, pp.175-184, 1994. 